\title{
Vaginal-assisted laparoscopic nerve sparing radical trachelectomy
}

\author{
(D) Cağatay Taşkıran ${ }^{1}$, (D) Selim Mısırlığlu1 ${ }^{1}$, (D) Doğan Vatansever1 , (D) Burak Giray², (D) Macit Arvas³ \\ 1Department of Obstetrics and Gynecology, Division of Gynecologic Oncology, Koç University Faculty of Medicine, İstanbul, Turkey \\ ${ }^{2}$ Clinic of Obstetrics and Gynecology, Zeynep Kamil Women and Children's Health Training and Research Hospital, \\ İstanbul, Turkey \\ 3Department of Obstetrics and Gynecology, İstanbul University-Cerrahpaşa, Cerrahpaşa Faculty of Medicine, \\ İstanbul, Turkey
}

\section{Abstract}

Fertility-sparing surgery has gained popularity in the last three decades for the management of cervical cancer in women under 40 years of age. Radical trachelectomy is a fertility-sparing surgical technique for women who wish to retain their fertility. Vaginal-assisted laparoscopic radical trachelectomy is feasible in selected patients with early cervical cancer. The aim of this video is to present a nerve-sparing vaginal-assisted laparoscopic radical trachelectomy demonstrating pelvic anatomical structures.

Keywords: Cervical cancer, fertility-sparing surgery, hypogastric nerve, laparoscopic radical trachelectomy, nerve-sparing surgery

Received: 30 June, 2019 Accepted: 2 December, 2019

\section{Introduction}

Nearly 25\% of all cervical cancers are diagnosed in women under 40 years of age (1). Radical trachelectomy by vaginal approach was the first technique to be successfully used (2). Several different procedures have since been described as fertility-sparing surgery techniques (3).

A 38 years-old nulliparous woman with high grade, keratinized, squamous cell carcinoma of the cervix was referred to our clinic. She had undergone a loop electrosurgical excision procedure at another center. The pathological review and clinical examination revealed a FIGO stage IB1 cervical carcinoma without lymphovascular space invasion and less than $2 \mathrm{~cm}$ in the greatest diameter. Abdomino-pelvic magnetic resonance imaging showed no residual disease after loop electrosurgical excision procedure. She underwent vaginalassisted laparoscopic surgery. One $25 \mathrm{mg} /$ vial kit of indocyanine green was reconstituted in $10 \mathrm{~mL}$ of aqueous solvent, and then a $2 \mathrm{~mL}$ aliquot was further diluted in $2 \mathrm{~mL}$ of aqueous solvent. Four $\mathrm{mL}$ of indocyanine green was injected into the uterine cervix at the 3 and 9 o'clock positions, submucosally and deep of the cervix to locate the sentinel lymph nodes. In the first step, the round ligaments were coagulated, cut and dissected from the anterior and posterior leaves of the broad ligament. The ureters were identified alongside the posterior leaf of the broad ligament. The uterine arteries were then ligated bilaterally at their origin from the hypogastric artery. Both paravesical and pararectal spaces were opened to gain access to the parametria. The anterior part of the vesicouterine ligament was dissected, and the ureteral tunnel was developed. Colpotomy was performed. All procedures were performed with meticulous dissection of pelvic anatomical structures including hypogastric nerves (Video 1) (Figure 1, 2). Resection of the cervix was performed during the vaginal part of the procedure. Frozen-section examination was performed to ensure negative surgical margins. Finally, the vaginal mucosa was sutured to

This surgical film is also accepted to be presented at $47^{\text {th }}$ American Association of Gynecologic Laparoscopists Global Congress on Minimally Invasive Gynecologic Surgery that will be held during 11-15 November, 2018 at Las Vegas, Nevada, United States of America. 


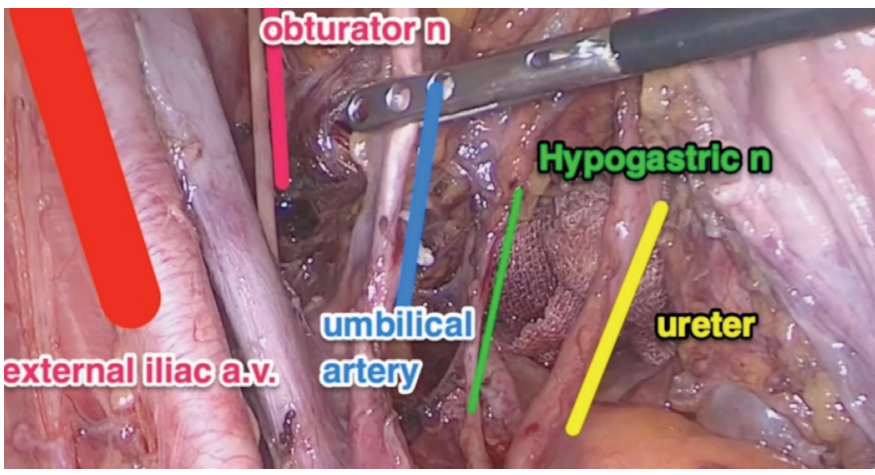

Figure 1. Left pelvic retroperitoneal space demonstrating left external iliac artery and vein, obturator nerve, obliterated umbilical artery, hypogastric nerve, and ureter

the stroma of the cervix. She was discharged on postoperative day four without any adverse event in the postoperative period. She had no residual tumor on final pathology. There was no metastasis on examination of the lymph nodes.

Vaginal-assisted laparoscopic nerve-sparing radical trachelectomy as a fertility-sparing procedure appears to be a safe and adequate surgical technique in selected young women with early stage cervical cancer.

\section{Video 1.}

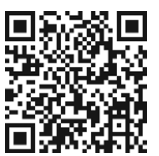

https://www.doi.org/10.4274/jtgga.galenos.2019.2019.0121.video1

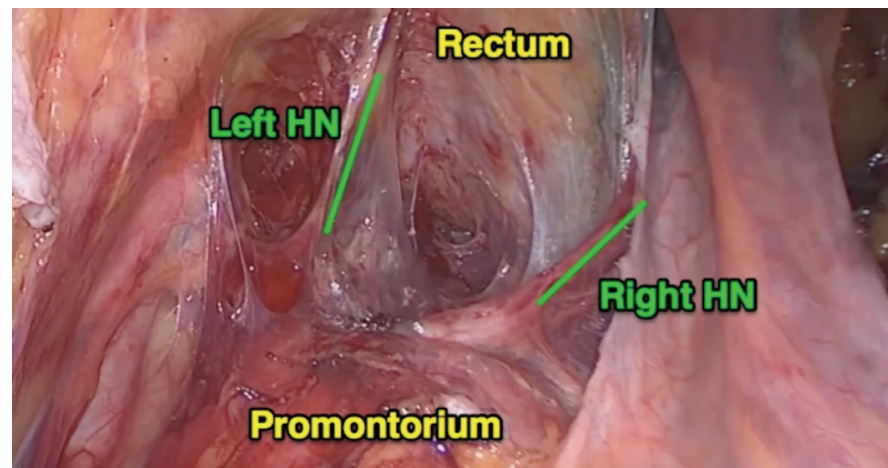

Figure 2. Retrorectal space demonstrating right and left hypogastric nerve

Conflict of Interest: No conflict of interest was declared by the authors.

Financial Disclosure: The authors declared that this study received no financial support.

\section{References}

1. Rob L, Skapa P, Robova H. Fertility-sparing surgery in patients with cervical cancer. Lancet Oncol 2011; 12: 192-200.

2. Dargent D, Martin X, Sacchetoni A, Mathevet P. Laparoscopic vaginal radical trachelectomy: a treatment to preserve the fertility of cervical carcinoma patients. Cancer 2000; 88 :1877-82.

3. Bentivegna E, Maulard A, Pautier P, Chargari C, Gouy S, Morice P. Fertility results and pregnancy outcomes after conservative treatment of cervical cancer: a systematic review of the literature. Fertil Steril 2016; 106: 1195-121. 